\title{
Obesity, adiposopathy, and quantitative imaging biomarkers
}

Obesidade, adiposopatia e biomarcadores de imagem quantitativa

Fernando Ide Yamauchi ${ }^{1}$, Adham do Amaral e Castro ${ }^{2}$

Obesity is a metabolic disease with increasing incidence at a global level. The prevalence of obesity doubled between 1980 and 2014, now corresponding to more than half a billion obese people worldwide $^{(1)}$. The World Health Organization estimates that more than a third of adults over 18 years of age are now overweight.

Obesity plays an important role in the development of several diseases, such as atherosclerosis, diabetes, musculoskeletal conditions (e.g., osteoarthritis, tendinopathy, and carpal tunnel syndrome), and chronic pain ${ }^{(2-5)}$. Another important association is the increased risk of cancer ${ }^{(6,7)}$. The development of these conditions is likely related to increased production of pro-inflammatory adipokines (e.g., interleukin 6 and tumor necrosis factor alpha) and decreased production of (or decreased tissue sensitivity to) anti-inflammatory adipokines (e.g., adiponectin). The final result is that those individuals are in an inflammatory state and show increased levels of acute phase reagents such as C-reactive protein $^{(8)}$.

In the field of radiology, there is a trend toward more quantitative science that could increase the value of quantitative imaging biomarkers and reduce variability across devices, patients, and time. A quantitative imaging biomarker can be defined as "an objective characteristic derived from an in vivo image measured on a ratio or interval scale as indicators of normal biological processes, pathogenic processes, or a response to a therapeutic intervention" ${ }^{(9,10)}$. It is extremely important that measurements can be reproduced by different observers on different equipment. In this context, the Radiological Society of North America has organized a Quantitative Imaging Biomarker Alliance.

There is great interest in quantitative measurements of adipose tissue, to serve as imaging biomarkers. Total body adipose tissue can be better understood and quantified through sectional imaging methods such as computed tomography and magnetic

1. MD, Attending Radiologist at Instituto de Radiologia do Hospital das Clínicas da Faculdade de Medicina da Universidade de São Paulo (InRad/HC-FMUSP), Attending Radiologist in the Department of Radiology, Hospital Israelita Albert Einstein, São Paulo, SP, Brazil. (E-mail: fernando.yamauchi@hc.fm.usp.br).

2. PhD, MD, Attending Radiologist in the Department of Radiology, Hospital Israelita Albert Einstein, Attending Radiologist in the Department of Diagnostic Imaging , Escola Paulista de Medicina da Universidade Federal de São Paulo (EPM-Unifesp), São Paulo, SP, Brazil. resonance imaging. It can be divided into two main categories: subcutaneous and internal. Internal fat can be further divided into two components: visceral and nonvisceral. The visceral component includes the adipose tissue distributed in three body cavities: thoracic, intra-abdominal, and pelvic. The nonvisceral component includes intermuscular and paravertebral adipose tissue ${ }^{(\mathbf{1 1})}$

Recent studies have demonstrated that deposition of visceral fat is an important imaging biomarker of metabolic disease ${ }^{(\mathbf{1 2 , 1 3 )}}$, linked to the concept of adiposopathy, also known as sick fat syndrome. Adiposopathy can be defined as "a pathologic adipose tissue anatomic/functional disturbances promoted by positive caloric balance in genetically and environmentally susceptible individuals which results in adverse endocrine and immune responses that both directly and indirectly contribute to metabolic disease and increased cardiovascular disease risk"(14).

In an article published in this issue of Radiologia Brasileira, Mauad et al. proposed using ultrasound and computed tomography to quantify abdominal fat and found correlations with body mass index, serum cholesterol, and abdominal circumference ${ }^{(15)}$. Although their study has certain limitations, the authors suggest that ultrasound might be used as an alternative method for abdominal fat quantification, with advantages including its wide availability, its lower cost, and the fact that it does not involve the use of ionizing radiation. It is important to notice that, in order to be considered suitable for quantitative imaging biomarkers, ultrasound measurements should be further correlated with cardiovascular events.

\section{REFERENCES}

1. WHO. Global status report on noncommunicable diseases 2014. Geneva: World Health Organization; 2015.

2. Moulin CM, Marguti I, Peron JP, et al. Impact of adiposity on immunological parameters. Arq Bras Endocrinol Metabol. 2009;53:183-9.

3. Seaman DR. Body mass index and musculoskeletal pain: is there a connection? Chiropr Man Therap. 2013;21:15.

4. Castro AA, Skare TL, Nassif PAN, et al. Tendinopathy and obesity. Arq Bras Cir Dig. 2016;29(Suppl 1):107-10.

5. Castro AA, Skare TL, Nassif PA, et al. Ultrasound evaluation on carpal tunnel syndrome before and after bariatric surgery. Rev Col Bras Cir. 2014;41:426-33.

6. Arnold M, Pandeya N, Byrnes G, et al. Global burden of cancer attributable to high body-mass index in 2012: a population-based study. Lancet Oncol. 2015; 16:36-46

7. Bhaskaran K, Douglas I, Forbes H, et al. Body-mass index and risk of 22 specific 
cancers: a population-based cohort study of $5 \cdot 24$ million UK adults. Lancet. 2014;384:755-65.

8. Ellulu MS, Khaza'ai H, Rahmat A, et al. Obesity can predict and promote systemic inflammation in healthy adults. Int J Cardiol. 2016;215:318-24.

9. Kessler LG, Barnhart HX, Buckler AJ, et al. The emerging science of quantitative imaging biomarkers terminology and definitions for scientific studies and regulatory submissions. Stat Methods Med Res. 2015;24:9-26.

10. Raunig DL, McShane LM, Pennello G, et al. Quantitative imaging biomarkers: a review of statistical methods for technical performance assessment. Stat Methods Med Res. 2015;24:27-67.

11. Shen W, Wang Z, Punyanita M, et al. Adipose tissue quantification by imaging methods: a proposed classification. Obes Res. 2003;11:5-16.
12. Wu CK, Yang CY, Lin JW, et al. The relationship among central obesity, systemic inflammation, and left ventricular diastolic dysfunction as determined by structural equation modeling. Obesity (Silver Spring). 2012;20:730-7.

13. Mathieu P, Poirier P, Pibarot $P$, et al. Visceral obesity: the link among inflammation, hypertension, and cardiovascular disease. Hypertension. 2009;53:57784

14. Bays H. Adiposopathy, "sick fat," Ockham's razor, and resolution of the obesity paradox. Curr Atheroscler Rep. 2014;16:409.

15. Mauad FM, Chagas-Neto FA, Benedeti ACGS, et al. Reprodutibilidade da avaliação da gordura abdominal pela ultrassonografia e tomografia computadorizada. Radio Bras. 2017;50:141-7. 